\title{
EKSTRAKURIKULER PRAMUKA TERINTEGRASI SIAGA BENCANA GEMPA BUMI TERHADAP KETERAMPILAN TANGGAP BENCANA SISWA SD
}

\author{
Delvia Puspadiningrum \\ Program Studi PGSD FKIP Universitas Bengkulu \\ Endang Widi Winarni \\ Program Studi PGSD FKIP Universitas Bengkulu \\ Hasnawati \\ Program Studi PGSD FKIP Universitas Bengkulu
}

\begin{abstract}
This study aims to determine the effect of extracurricular scouting integrated standby earthquake disaster response skill alert for elementary school students in the city of Bengkulu. This research is a quantitative research. The research design used is The Matching Only Pretest-posttest Control Group Design, the population in this study all the scout participants in SD Negeri Kota Bengkulu. The selected research sample is SD Negeri 02 Kota Bengkulu as Experiment and SD Negeri 19 Kota Bengkulu as the control. The research instruments used are observation sheets given through pretest (before activity) and posttest (after activity). Data of this research are analyzed by using descriptive and inferential analysis that is $t$-test. From the research results it is known that the average value of experimental group posttest is 80 control group equal to 57.2. The result of t-test with tcount is 9,785 and ttabel 2,306. So thitung >ttable, so it can be concluded that there is an extracurricular influence of integrated scouting education on earthquake disaster preparedness to disaster response preparedness skills of elementary school students in BengkuluCity.
\end{abstract}

Keywords: Extracurricular scouting education, earthquake disaster, Disaster preparedness skills.

\section{PENDAHULUAN}

Pasal 3 Undang-Undang Republik Indonesia Nomor 20 Tahun 2003 tentang sistem pendidikan nasional menyebutkan bahwa pendidikan nasional bertujuan untuk berkembangnya potensi siswa agar menjadi manusia yang beriman dan bertakwa kepada Tuhan Yang Maha Esa, berakhlak mulia, sehat, berilmu, cakap, kreatif, mandiri, dan menjadi warga negara yang demokratis serta bertanggung jawab. Pengembangan potensi siswa sebagaimana dimaksud dalam tujuan pendidikan nasional dapat diwujudkan melalui kegiatan ekstrakurikuler.
Peraturan daerah nomor 03 tahun 2010 telah membentuk Badan Penanggulangan Bencana Daerah (BPBD) Kota Bengkulu yang merupakan perangkat daerah kota yang dibentuk dalam rangka melaksanakan tugas dan fungsi untuk melaksanakan penanggulangan bencana. Pada pasal 25 ayat E menyatakan bahwa BPBD (Badan Penanggulangan Bencana Daerah) bertugas untuk mensosialisasikan kepada masyarakat tentang kesiapsiagaan masyarakat dalam menanggapi bencana melalui media massa, leaflet, selebaran,atau simulasi gempa. Salah satu programnya yaitu melakukan simulasi bencana gempa bumi di sekolah berbasis siaga bencana 
Kegiatan-kegiatan pendidikan gerakan pramuka dilaksanakan di alam terbuka (Outdoor Activity) berupa permainan yang menarik, menantang serta mengandung nilai-nilai pendidikan siaga bencana bagi segenap anggota (peserta).Anggota pramuka dilatih agar berkepribadian utuh, mandiri, memiliki kemampuan memimpin dan bekerjasama serta berbagai kecakapan lain yang sangat perlu bagi pertumbuhan generasi muda (Manalu,2014: 2).

Dalam Undang-undang Republik Indonesia Nomor 24 Tahun 2007 telah membentuk Badan SAR Nasional (BASARNAS) Kota Bengkulu yang merupakan Badan Penyelamatan Bencana Alam. Badan SAR Nasional berinisiatif untuk memberikan bekal keterampilan kepada siswa sekolah tentang cara menyelamatkan diri berikut dalam memberikan pertolongan pertama kepada korban bencana.

Setiap peserta pramuka wajib dibekali dengan keterampilan tanggap siaga bencana. Adapun bentuk program tanggap siaga bencana yang ada di dalam ekstrakurikuler pendidikan kepramukaan yaitu terletak pada materi pionering. Pada materi ini siswa diajarkan bagaimana cara membuat tandu siaga bencana yang merupakan alat untuk mengevakuasi korban bencana,serta cara mengevakuasi korban bencana dari lokasi kejadian yang terkena bencana ke tempat evakuasi yang aman dari bencana. Melalui kegiatan ini tertanam jiwa keterampilan tanggap siaga bencana pada diri siswa. Bahwa keterampilan tanggap siaga bencana meningkatkan keterampilan peserta didik agar terwujud penanganan bencana yang cepat, tanggap dan efektif. Agar peserta didik menyadari pentingnya kesiapsiagaan yang solid bilamana sewaktu-waktu terjadi bencana yang tidak terduga.

\section{METODE}

Dalam penelitian ini digunakan jenis penelitian kuantitatif. Metode dalam penelitian ini adalah metode eksperimen, yang digunakan adalah quasi experiment (eksperimen semu). Penelitian ini dikategorikan eksperimen semu dengan desain penelitian menggunakan The Matching Only Pretest-Postest Group.

Di mana dalam penelitian ini dipilih SD Negeri yang berstandar nasional dengan peringkat akreditasi A yang terdiri dari 12 SD Negeri yaitu SD Negeri 01, SD Negeri 02, SD Negeri 5, SD Negeri 9, SD Negeri 11, SD Negeri 19, SD Negeri 20, SD Negeri 42, SD Negeri 52, SD Negeri 67, SD Negeri 68, dan SD Negeri 71. Alasan dipilih sekolah ini karena sekolah yang berstandar nasional yang paling banyak jenisnya. Teknik pengambilan sampel dalam penelitian ini adalah teknik cluster Random Sampling. Maka, untuk menentukan sampel pada penelitian ini, seluruh populasi yang ada diundi sehingga didapat SD Negeri 02 kota Bengkulu sebagai sekolah eksperimen dan SD Negeri 19 Kota Bengkulu sebagai sekolah kontrol.

Dalam penelitian ini instrumen yang digunakan berupa lembar observasi. Lembar observasi ini terlebih dahulu akan dianalisis validitas dan reliabilitas melalui uji coba instrumen. Uji coba instrumen bertujuan untuk mengetahui kelayakan instrumen untuk dijadikan instrumen penelitian. Pada penelitian ini, uji validitas instrumen dilakukan dengan cara memvalidasi lembar observasi kepada ahli yaitu bapak Riyadi Santoso, S.Pd. Dan uji coba instrumen di SD Negeri 68 kota Bengkulu.

Teknik pengumpulan data dalam penelitian ini adalah pemberian berupa lembar observasi. Lembar observasi ini terdiri dari pretest dan posttest. Bentuk pretest dan posttest yang digunakan adalah lembar observasi yang diisi oleh peneliti yang terdiri dari 12 indikator.Teknik analisis data yang digunakan dalam penelitian ini adalah analisa kuantitatif yang terdiri dari analisis statistik deskriptif meliputi perhitungan skor rata (Mean), varian, penyajian data melalui tabel, dan lain-lain, uji prasyarat meliputi uji normalitas dan uji homogenitas, serta uji-t. 


\section{HASIL}

\section{Hasil data pretest}

Pemberian lembar pretest ini dilakukan pada kelompok yang menjadi sampel penelitian yaitu SD Negeri 02 Kota Bengkulu sebagai sekolah eksperimen dan SD Negeri 19 Kota Bengkulu sebagai sekolah kontrol sebelum melaksanakan kegiatan ekstrakurikuler pendidikan kepramukaan terintegrasi siaga bencana.dari perhitungan rata-rata menunjukkan bahwa nilai rata-rata pretest pada kelompok kontrol sebesar 34,4 dan kelompok eksperimen sebesar 36,4.

Hasil dari perhitungan uji normalitas hasil keterampilan tanggap siaga bencana pretest pada kelompok sampel menunjukkan bahwa nilai $\chi^{2}$ hitung kelompok kontrol sebesar 0,1784 dan $\chi^{2}$ hitung kelompok eksperimen sebesar 0,1784. Nilai $\chi^{2}$ tabel pada taraf signifikan $5 \%$ sebesar 5,991 . Artinya hasil kelompok kontrol $\chi^{2}$ hitung $(0,1784)<\chi^{2}$ tabel $(5,991)$. Sedangkan kelompok eksperimen $\chi^{2}$ hitung $(0,1784)<\chi^{2}$ tabel $(5,991)$. Hasil ini memberikan indikasi bahwa hasil keterampilan tanggap siaga bencana pretest sampel penelitian berdistribusi Normal.

Berdasarkan data hasil perhitungan homogenitas pretest menunjukkan bahwa nilai $\mathrm{f}_{\text {hitung }}$ sebesar 1 lebih kecil daripada $\mathrm{f}_{\text {tabel }}$ pada taraf signifikan $5 \%$ sebesar 8,38 . Artinya $f_{\text {hitung }}$ (1) $<\mathrm{f}_{\text {tabel }}(8,38)$. Hasil ini memberikan indikasi bahwa keterampilan tanggap siaga bencana pretest eksperimen dan kontrol berasal dari varian yang Homogen.

Hasil pengujian hipotesis terhadap data keterampilan tanggap siaga bencana pretest menunjukkan bahwa nilai $t_{\text {hitung }}$ sebesar 1,26 lebih kecil daripada nilai $t_{\text {tabel }}$ pada taraf signifikan $5 \%$ yaitu sebesar 2,306. Karena nilai $\mathrm{t}_{\text {hitung }}(1,26)<\mathrm{t}_{\text {tabel }}(2,306)$ berarti $\mathrm{H}_{0}$ diterima dan $\mathrm{H}_{\mathrm{a}}$ ditolak, artinya tidak terdapat perbedaan keterampilan tanggap siaga bencana pada saat sebelum melaksanakan ekstrakurikuler pendidikan kepramukaan terintegrasi siaga bencana gempa bumi dan setelah melaksanakan ekstrakurikuler pendidikan kepramukaan terintegrasi siaga bencana gempa bumi.

\section{Hasil data posttest}

Pemberian lembar posttest ini dilakukan pada sekolah yang menjadi sampel penelitian yaitu SD Negeri 02 Kota Bengkulu sebagai sekolah eksperimen dan SD Negeri 19 Kota Bengkulu sebagai sekolah kontrol sesudah melaksanakan kegiatan ekstrakurikuler pendidikan kepramukaan terintegrasi siaga bencana. dari perhitungan rata-rata menunjukkan bahwa nilai rata-rata posttest pada kelompok eksperimen lebih tinggi dari kelompok kontrol. Nilai posttest pada kelompok kontrol adalah 57,2 dan nilai posttest pada kelompok eksperimen adalah 80 , sehingga selisih keduanya adalah sebesar 23,2.

Hasil dari perhitungan uji normalitas hasil keterampilan tanggap siaga bencana posttest pada kelompok sampel menunjukkan bahwa nilai $\chi^{2}$ hitung kelompok kontrol sebesar 1,489 dan $\chi^{2}$ hitung kelompok eksperimen sebesar 1,489. Nilai $\chi^{2}$ tabel pada taraf signifikan 5\% sebesar 5,991. Artinya hasil kelompok kontrol $\chi^{2}$ hitung $(1,489)$ $<\chi^{2}$ tabel (5,991). Sedangkan kelompok eksperimen $\chi^{2}$ hitung $(1,489)<\chi^{2}$ tabel $(5,991)$. Hasil ini memberikan indikasi bahwa keterampilan tanggap siaga bencana posttest sampel penelitian berdistribusi Normal.

Sedangkan Berdasarkan data hasil perhitungan homogenitas posttest menunjukkan bahwa nilai $f_{\text {hitung }}$ sebesar 2,78 lebih kecil daripada $\mathrm{f}_{\text {tabel }}$ pada taraf signifikan $5 \%$ sebesar 8,38. Artinya $\mathrm{f}_{\text {hitung }}(2,78)<\mathrm{f}_{\text {tabel }}(8,38)$. Hasil ini memberikan indikasi bahwa keterampilan tanggap siaga bencana posttest eksperimen dan kontrol berasal dari varian yang Homogen.

Hasil pengujian hipotesis terhadap data keterampilan tanggap siaga bencana posttest menunjukkan bahwa nilai $t_{\text {hitung }}$ sebesar 9,785 lebih besar daripada nilai $t_{\text {tabel }}$ pada taraf signifikan 5\% yaitu sebesar 2,306. Karena nilai $t_{\text {hitung }}(9,785)>t_{\text {tabel }}(2,306)$ berarti $H_{0}$ ditolak dan $\mathrm{H}_{\mathrm{a}}$ diterima, artinya terdapat perbedaan keterampilan tanggap siaga bencana pada saat sebelum melaksanakan ekstrakurikuler pendidikan kepramukaan terintegrasi siaga bencana gempa bumi dan setelah melaksanakan 
ekstrakurikuler pendidikan kepramukaan terintegrasi siaga bencana gempa bumi.

\section{PEMBAHASAN}

Hasil penelitian dan uji hipotesis yang telah dilakukan menunjukkan bahwa dengan melaksanakan ekstrakurikuler pendidikan kepramukaan terintegrasi siaga bencana gempa bumi memberikan pengaruh terhadap keterampilan tanggap siaga bencana siswa SD Negeri di Kota Bengkulu. Hal ini menunjukkan bahwa hasil perbandingan dalam kegiatan inti yang membedakan pada kegiatan ekstrakurikuler pendidikan kepramukaan terintegrasi siaga bencana gempa bumi terhadap keterampilan tanggap siaga bencana, bahwa pada sekolah eksperimen di SD Negeri 02 Kota Bengkulu kegiatan ekstrakurikuler pendidikan kepramukaan siaga bencana gempa bumi dengan setiap latihan dilakukan simulasi bencana gempa bumi secara terintegrasi, sedangkah di sekolah kontrol SD Negeri 19 Kota Bengkulu kegiatan ekstrakurikuler pendidikan kepramukaan siaga bencana gempa bumi diawali dengan pemberian materi lalu terakhir diberi simulasi gempa bumi.Perbandingan perlakuan di sekolah eksperimen menunjukkan di kegiatan awal siswa yaitu mengikuti (TUS) tata upacara siaga, pada saat di dalam kelas peserta pramuka beserta pembina pramuka dan peneliti menonton video gempa bumi dengan melakukan simulasi gempa bumi.Lalu melakukan kegiatan mengenal simpul: (1) simpul pangkal; (2) simpul jangkar; (3) simpul hidup dan (4) ikatan palang dengan melakukan simulasi gempa bumi. Lalu mengaplikasikan tali temali dalam pembuatan tandu siaga bencana dengan simulasi gempa bumi, pada pertemuan berikutnya anggota SAR memberi materi siaga bencana kepada peserta pramuka dengan simulasi gempa bumi, pada pertemuan selanjutnya peserta pramuka yang didamping oleh pembina pramuka, pembina saka wira kartika, SAR dan peneliti melakukan simulasi gempa bumi dengan standar operasional prosedur (SOP) di dalam kelas. Lalu memberikan penyelamatan, penanganan korban di lapangan terbuka yang jauh dari reruntuhan setelah itu peserta pramuka melakukan pengembalian rasa trauma pada korban bencana dengan menghibur korban yang terkena bencana, terakhir melakukan upacara penutupan siaga (TUS).

Sedangkan pada sekolah kontrol di kegiatan awal melakukan (TUS) tata upacara siaga, pada saat di dalam kelas peserta pramuka beserta pembina pramuka dan peneliti menonton video gempa bumi. Lalu melakukan kegiatan mengenal simpul: (1) simpul pangkal; (2) simpul jangkar; (3) simpul hidup dan (4) ikatan palang, lalu mengaplikasikan tali temali dalam pembuatan tandu siaga, pada pertemuan berikutnya anggota SAR memberi materi siaga bencana kepada peserta pramuka, pada pertemuan selanjutnya peserta pramuka yang didamping oleh pembina pramuka, pembina saka wira kartika, SAR dan peneliti melakukan simulasi gempa bumi dengan (SOP) di dalam kelas. Lalu memberikan penyelamatan, penanganan korban di lapangan terbuka yang jauh dari reruntuhan setelah itu peserta pramuka melakukan pengembalian rasa trauma pada korban bencana dengan menghibur korban yang terkena bencana, terakhir melakukan upacara penutupan siaga (TUS). Yang membedakannya adalah pada kegiatan inti di sekolah eksperimen melaksanakan ekstrakurikuler pendidikan kepramukaan terintegrasi siaga bencana gempa bumi setiap pemberian materi dan kegiatan dilaksanakan simulasi gempa bumi sedangkan kelompok kontrol yang membedakannya pada pemberian materi dan kegiatan terlebih dahulu lalu terakhir melaksanakan simulasi gempa bumi. Maka, terdapat pengaruh yang signifikan pada ekstrakurikuler pendidikan kepramukaan terintegrasi siaga bencana gempa bumi terhadap keterampilan tanggap siaga bencana.

Hal ini didukung oleh pendapat Winarni, dkk (2009: 20) menujukkan bahwa aspek yang dipertimbangkan di dalam pendidikan kesiapsiagaan bencana: (1) berbasis lingkungan, siswa diajak untuk bersahabat dengan alam sekitar; (2) mempunyai nilai aplikatif yang tinggi, langsung menerapkan keterampilan yang diperlukan saat bencana. 
Hasil uji perbedaan posttest antara kelompok eksperimen dan kelompok kontrol menunjukkan $t_{\text {hitung }}(9,785)$ lebih besar dari $t_{\text {tabel }}$ $(2,306)$ artinya $\mathrm{H}_{0}$ ditolak dan $\mathrm{H}_{\mathrm{a}}$ diterima. Artinya terdapat perbedaan yang signifikan pada kedua kelompok ini sehingga dapat ditarik kesimpulan bahwa terdapat pengaruh yang signifikan pada posttest antara kelompok eksperimen dan kelompok kontrol. Jadi, pada penelitian ini esktrakurikuler pendidikan kepramukaan terintegrasi siaga bencana gempa bumi memberikan pengaruh yang signifikan terhadap keterampilan tanggap siaga bencana siswa SD Negeri di Kota Bengkulu.

\section{SIMPULAN}

Berdasarkan hasil penelitian dapat disimpulkan bahwa terdapat pengaruh ekstrakurikuler pendidikan kepramukaan terintegrasi siaga bencana gempa bumi terhadap keterampilan tanggap siaga bencana siswa SD Negeri di Kota Bengkulu. Hal ini ditunjukkan dengan hasil uji perbedaan posttest kelompok eksperimen dan kelompok kontrol dengan nilai $t_{\text {hitung }}$ sebesar 9.785 dan $t_{\text {tabel }} 2.306$ dengan demikian pengujian hipotesis uji-t nilai posttest kelompok eksperimen dan kelompok kontrol adalah $t_{\text {hitung }}>t_{\text {tabel }}$ artinya terdapat perbedaan yang signifikan. Hal ini dibuktikan pada kelompok eksperimen dan kelompok kontrol saat melakukan kegiatan awal TUS (Tata upacara siaga) terdapat sama tidak ada perbedaan pada kegiatan upacara pembukaan siaga dan penutupan siaga, sedangkan pada kegiatan inti sama-sama melakukan kegiatan sesuai (SOP) tetapi yang membedakan kelompok eksperimen pada saat pemberian materi dilakukan simulasi gempa bumi serta melaksanakan kegiatan dilakukan simulasi gempa bumi sedangkan kelompok kontrol diberi materi dan kegiatan terlebih dahulu. Terakhir melakukan simulasi gempa bumi, setelah melaksanakan ekstrakurikuler pendidikan kepramukaan terintegrasi siaga bencana gempa bumi dapat membantu siswa dalam menanggapi resiko terjadi bencana, dan meningkatkan keterampilan tanggap siaga bencana.

\section{SARAN}

1. Bagi kepala sekolah untuk dapat memerintahkan pembina pramuka dalam melatih siswa agar terampil tanggap siaga bencana dalam kegiatan ekstrakurikuler pendidikan kepramukaan terintegrasi siaga bencana.

2. Bagi pembina pramuka agar dapat melatih keterampilan tanggap siaga bencana pada perserta pramuka dalam kegiatan ekstrakurikuler pendidikan kepramukaan terintegrasi siaga bencana.

3. Bagi siaga pramuka agar dapat melakukan keterampilan tanggap siaga bencana dalam kegiatan ekstrakurikuler pendidikan kepramukaan teritegrasi siaga bencana sesuai dengan SOP (standar operasional prosedur).

4. Bagi peneliti lain (yang ingin menindaklanjuti penelitian ini) disarankan untuk dapat melakukan keterampilan lainnya dalam kegiatan ekstrakurikuler pendidikan kepramukaan teritegrasi siaga bencana.

\section{DAFTAR PUSTAKA}

Krisna A. 2011. Bencana Alam dan Global Warning. Bekasi: CV Rafa Aksara.

Manalu, Mario P, dkk. 2014. Gerakan Pramuka Mempersiapkan Generasi Muda. Jakarta: Penerbit Lestari Kiranatama.

Peraturan Daerah Kota Bengkulu, 2010, Badan Penanggulangan Bencana Daerah Kota Bengkulu, Bengkulu:Walikota Bengkulu.

Rahayu, Harkunti, dkk. 2003. Program kesiapan sekolah terhadap bahaya gempa. Jakarta: Litbang Integrsi dan Aplikasi (Eks PPAU) Lt. 8.

Republik Indonesia.(2010). Penanggulangan Bencana Undang-undang Republik Indonesia No. 24 Tahun 2007. Jakarta: Penerbit Kwartir Nasional Gerakan Pramuka.

Sar Goes to School. (2011). Search and Rescue. Jakarta: Penerbit Badan SAR Nasional.

Tim Kementerian Pendidikan dan Kebudayaan. 2013. Peraturan Menteri Pendidikan dan Kebudayaan Republik Indonesia nomor 81 A tahun 2013 tentang implementasi kurikulum (pedoman kegiatan ekstrakurikuler). Jakarta: kemendikbud. 
Ummah, Khairul. 2013. Kami Pramuka Indonesia. Jakarta: PT Masmedia Buana Pustaka (Anggota IKAPI).

Winarni, Endang Widi. 2011. Penelitian Pendidikan. Bengkulu: Unit Penerbitan FKIP UNIB.

Winarni, Endang Widi. 2016. Pengembangan pembelajaran tematik integratif pengurangan risiko bencana (PRB) berbasis ICT untuk pembudayaan sikap dan keterampilan siaga bencana bagi siswa sekolah dasar. Lembaga penelitian Unib: Laporan akhir penelitian strategis nasional. Tahun kedua.
Yulaelawati, Ella, dkk. 2008. Mencerdasi Bencana. Jakarta: Penerbit PT Grasindo Anggota Ikapi.

Winarni, Endang Widi. 2014. " Upaya peningkatan self education di sekolah dasar melalui program pengurangan risiko bencana (PRB) dalam kegiatan ekstrakurikuler pramuka. Lembaga penelitian Unib.

Indriasari. 2014. "Pengaruh pelatihan siaga bencana gempa bumi terhadap kesiapsiagaan anak sekolah dasar dalam menghadapi bencana". Yogyakarta. 